\title{
L2 WRITING DEVELOPMENT: THE CASE OF TWO HIGH-ACHIEVING AND TWO STRUGGLING COLLEGE-LEVEL STUDENTS
}

\author{
HICHAM ZYAD 1 \\ Hassan II University, Morocco
}

\begin{abstract}
Researchers and language practitioners have long been interested in the quest for theory-based, research-supported constructs that can adequately characterize L2 writing proficiency and development. The ongoing scholarly inquiry in this research area has led to the mounting recognition that complexity, accuracy and fluency (henceforth, CAF) constitute a conceptual framework capable of charting L2 writing proficiency and benchmarking development. Against this background, the present study aims to investigate four college-level semester-one students' L2 writing development over a time frame of twelve weeks. Couched within the constructivist paradigm, which advocates learner independence, meaningful learning and collaboration, the study examines the extent and nature of the progress that two highachieving L2 students made as compared with two struggling peers with regard to their written productions. On the basis of case study methodology, a thick description is provided for each student on account of his measurable progress as assessed by theoretically motivated indices of complexity and accuracy. The paper also explores the time spent on online Moodle activities by the four participants to ascertain whether or not a relationship existed with the progress made. Complexity was measured by mean length of t-unit, mean length of clause and number of clauses per t-unit; accuracy was measured by mean number of error-free t-units and the ratio of error-free $t$-units to total number of $t$-units. The writing program in which the participants were engaged was based on the use of Moodle as a platform where students have access to myriad supplementary materials including website links, videos, PowerPoint slides, book chapters and exercises handouts. They were also required to post their written assignments in the Moodle-hosted blog and to participate in forums designed for the exchange of feedback. The implications of the results for $L 2$ writing instruction are discussed.
\end{abstract}

Key words: ELT, L2 writing pedagogy, complexity, accuracy, ICT.

\section{Introduction \& Background}

Arguably, no other language skill is more complex than writing (Verspoor et al., 2008; de Groot, 2012, Skehan, 2009). Theoretical and empirical evidence exists suggesting that writing is multilayered, including sentence-level and discourse-level skills, stylistic and pragmatic awareness, genre literacy and selfregulated strategy development (Haoucha, 2005). For this reason, besides the intensive unguided freewriting activity recommended by the process-oriented, expressivist approach, writing skills development requires systematic and rigorous guided instruction. Guided L2 writing instruction presupposes that learners are provided with personalized feedback to meet individual students' special learning needs. However, growing student populations in Moroccan universities in general, and in English departments in particular, make it extremely difficult for writing teachers to offer such personalized feedback (Ennaji, 2005). This leaves large numbers of students grapple with the intricacies and complexities of $L 2$ writing acquisition on their own. Worse still, limited class time aggravates the situation even further as writing teachers can do very little to ensure that students continue to practice writing outside class time. Assuming that students do continue to practice writing outside class time, the outcome is oftentimes unpromising as students will have to work in isolation from their peers and their teacher. No wonder, lack of students' engagement, which has been found to bear on the quality of their learning (Wong, 2013), leads to demotivation, frustration and eventually failure to subsist in the writing course. Such a situation calls for research aimed at exploring the effectiveness of instructional procedures of writing that can respond to all the concerns outlined above.

\footnotetext{
1 Email: Zyadhicham@ymail.com
} 
The majority of the studies that attempt to examine the effectiveness of writing instructional procedures have been carried out within a quasi-experimental research design in Moroccan tertiary education. While this line of research produces numeric, generalizable data, it falls short of providing a detailed account of the effects of the model of writing instruction being tested on individual students' writing development. Another limitation of quasi-experimental designs is that students' mean score gains tend to be influenced by outliers and therefore several prominent aspects of students' writing performance remain unexplored. Due to these concerns, the present study uses case study methodology to investigate L2 writing development of four college-level semester-one students over twelve weeks. More precisely, the study aims to probe the extent and nature of the progress that two high-achieving L2 students made as compared with two struggling peers with regard to their written productions. It also seeks to explore the extent of students' engagement with the online Moodle-hosted activities and its impact on their writing ability. These objectives were operationalized into three research questions:

1. What is the impact of a blended learning environment on the writing complexity and accuracy of two L2 high-achievers as compared with two struggling students working collaboratively in the same group?

2. What is the nature of the growth in complexity and accuracy attained by the four students?

3. To what extent does these students' engagement with the online Moodle platform bear on the progress made in complexity and accuracy?

The paper begins by introducing the theoretical framework within which the study is situated as well as a review of relevant literature. This will be followed by a description of the methods and instruments used alongside the procedure implemented in the model of writing instruction proposed in the study. Subsequently, the results will be presented and discussed in accord with previous research studies. Finally, the study will be concluded with a number of implications for the teaching of writing in postsecondary education.

\section{Constructivism}

Constructivism is a theoretical paradigm that includes several theories with crucial implications for classroom pedagogy (Palincsar, 1998). Growing disenchantment with traditional Western conceptions of knowledge generation has led to the emergence of Constructivism, which thus stands in stark contrast to objectivist epistemology and positivism. The versions of constructivism range along a continuum from trivial constructivism to radical constructivism. Trivial constructivism maintains that knowledge is constructed by individuals and that research should be concerned with whether or not such constructions are correct representations whereas radical constructivism dismisses objective knowledge and holds that knowledge results from dialogue among people in society. Despite the multiple positions in constructivism, the following discussion will focus on Piaget's and Vygotsky's theorizing and how they have affected conceptions about learning.

According Piaget, knowledge and understanding are generated by the unconscious activation of several processes set in motion each time individuals encounter information captured by any of their senses (Pritchard \& Woollard, 2010). These processes are assimilation, accommodation and equilibration. Assimilation results from the addition of new information to already existing schemata. When the incoming information conflicts with internal cognitive structures, accommodation modifies or transforms these structures in order to establish a state of equilibrium. Learners confronted with a new situation may resort to one of three different types of accommodation. They may ignore the conflicting information and cling to already existing schemata; they may oscillate by maintaining the contradiction and viewing it as reflecting separate or distinct cases; or they may modify their earlier understanding of the phenomenon in question to attain a sense of balance with the surrounding environment.

Regarding Vygotsky's views of knowledge construction and learning, he theorizes that cognitive and intellectual growth is a corollary result of social interaction, thus placing special emphasis on the dialogue that takes place among people as they go about their daily lives. Vygotsky (1978) argues that "every function in the child's cultural development appears twice: first, on the social level, and later, on the individual level" (p. 57). Central to Vygotskian thinking is the concept of the zone of proximal development (ZPD), which he contends is the space between what a learner can do independently and what the learner can do only with the assistance of 
a more knowledgeable other. At this level, the role of social interaction becomes evident as the dialogic assistance between more knowledgeable members of the community and novice learners brings them to new ZPDs, representing higher levels of understanding and cognitive maturity. This more knowledgeable other does not have to be the teacher or an adult but a high-achieving peer can play this role by helping struggling classmates in the context of group or pair work (Pritchard \& Woollard, 2010).

Constructivism is a theoretical framework primarily concerned with learning, not teaching. However, constructivist principles of learning can be made to yield several useful prescriptions for teaching (Palincsar, 1998). Drawing on constructivist theories of learning, instruction should therefore abandon the practice of uprooting ideas and concepts from their context for teaching purposes. Alternatively, teachers should create a learning environment that provide learners with meaningful and concrete experiences where they can identify patterns, pose questions, solve problems and structure their own models, concepts and strategies. The classroom should then be pictured as a society in miniature where learners collaboratively engage in problem-solving situations and attempt to solve them through dialogue and the joint negotiation of meaning. These assumptions and principles have been put to intensive research activity in the domain of second language acquisition, particularly in empirical investigations of the effects of collaborative onsite and online learning environments to which we now turn for a review.

\section{Onsite collaborative writing}

A large body of empirical research has concerned itself with the effects of collaboration on the quality of learners' written productions. In the Moroccan context, Haoucha (2005) investigated whether process writing is more effective when implemented collaboratively or individually. She experimented with four different types of feedback: self-monitored feedback, peer feedback, teacher feedback and taped feedback. One major result was that collaborative peer feedback was a valuable aid not only in encouraging the students to revise multiple drafts but also in having other linguistic, cognitive and affective benefits. By means of a dictogloss task, Kuiken and Vedder (2012) tested the hypothesis that collaborative writing activities more positively affect learners' text reconstruction quality than individual writing activities. The study focused on the grammatical and lexical complexity of the collaboratively reconstructed text as well as the strategies employed by the learners as they negotiate their way through the task. It was found that the three groups varied with regard to the use of strategies as well as attention to form, the lexicon and the mechanics of writing. The inconsistency among the learners was attributed to several factors such as the cross-sectional design, learners' L2 proficiency and the nature of the tasks. Another study that probed the effects of collaboration on text quality is Dobao (2012), who examined the impact and nature of the oral interactions among group, pair and individual participants on the complexity, accuracy and fluency of their compositions. Group collaboration was found to be more effective than pair collaboration in terms of accuracy. While it was reported that individual learners produced longer texts, no clear differences were found among the three groups in terms of syntactic and lexical complexity.

Along the same line of research, Neumann and McDonough (2014) investigated the relationship between learners' interactions during collaborative prewriting tasks and their written texts alongside the writing aspects attended to when they engaged in collaborative dialogue about their own writings. As the researchers compared the results of two related studies, they found that structured prewriting tasks in Study two were more effective than naturally-occurring discussions among the students in Study one. They did not find any positive correlation between amount of reflective episodes in prewriting activities and the quality of students' texts. On the basis of a proposed instructional writing methodology called dynamic written corrective feedback, Hartshorn et al. (2010) assigned two groups of students to two conditions: one exposed to conventional writing instruction and the other to a proposed model. It was reported that the mean score gains related to accuracy notably increased in the treatment group, which is based on the collaborative exchange of written corrective feedback. However, rhetorical competence, complexity and fluency did not yield any significant results.

Additionally, Wigglesworth and Storch (2009) examined the impact of collaborative pair work writing activities on complexity, accuracy and fluency. Again, it was found that the pair work condition produced significant results with regard to accuracy but it did not positively affect complexity and fluency. Similar findings were reported in Storch (2005), who explored the nature of the collaborative discussions that transpire during 
the writing process by comparing texts produced by pairs of students and texts produced by students working individually. Although the collaboratively produced compositions were short, they were more effective at the level of task fulfillment, grammatical accuracy, and complexity. Despite a few reservations on collaborative writing, the majority of the students had a positive attitude towards the experience.

\section{Online collaborative writing}

Undoubtedly, the affordances of social networking technologies for collaborative L2 writing have opened up new avenues of empirical research. To illustrate, Tuzi (2004) explored the impact of electronic feedback on students' revisions with special emphasis on how peers responded to their partners and the nature of the revisions made. While the students expressed preference for the oral face-to-face feedback, written e-feedback had a greater impact on revisions. E-feedback was also observed to draw the students' attention to larger units of writing, implying that e-feedback can be useful in macro-revisions of students' writing samples. Similarly, Zhang et al. (2014) reported on the positive effects of blog-mediated collaborative writing. They found that the exchange of peer feedback on a blog platform had statistically positive correlations with motivation, collaboration and course satisfaction. This experience gave the students ample time to reflect on their language and also raised their confidence in expressing themselves in L2 writing.

Additionally, Jones et al (2006) investigated the dynamics of group interactions by comparing online and onsite peer-tutoring of writing in a Hong Kong university. The study uncovered several differences between these two modes of interactive writing. That is, onsite face-to-face interactions were characterized by hierarchically unequal relationships between the tutors, who monopolized the conversations, and the clients, who assumed a more passive role. It was also found that more emphasis was laid on grammar, vocabulary and style in face-to-face interactions while the online mode directed the students' attention to more global issues such as content and the process of writing. Similar results were reported in Liu and Sadler (2003), who examined the relationship between mode of interaction (technology-mediated or face-to-face) and attention to the area, type and nature of comments given by peer-reviewers. The results showed that the online mode emulated the onsite mode in terms of number of comments, percentage of revision-oriented comments and the overall number of revisions made. Because the study found that onsite interactions were also of value in some respects, the researchers concluded that a blended environment where a sequence of onsite and online writing activities is used may be more effective than a single mode.

Seeking to explore and understand the nature of collaborative writing, Kessler et al. (2012) investigated web-based, project-oriented, many to many collaborative writing. They reported that the participants focused more on meaning than form and that the grammatical changes they made were more accurate than inaccurate. Besides, the students showed inconsistency in terms of participation frequency and used the web-based tool simultaneously for multiple purposes. The application of the changes the students made was fluid and iterative in the sense that they did not wait until they finished to attend to formatting issues. In another study, Elola and Oskoz (2010) researched the relationship between students' wiki-based collaborative writing and the quality of their written productions. No statistically significant differences were found between individual and online collaborative writing in terms of complexity, accuracy and fluency. However, the study cast light on the nature of the interactions with regard to the text as a function of whether the task is carried out individually or in groups.

\section{Methods and materials}

\subsection{Context of the study}

The study took place in Hassan II University, the School of Humanities in Ben M'sik, Morocco. The English department accommodates around 330 semester-one students divided into three groups, with each having a different writing instructor. The writing course in question is called paragraph writing and aims to equip the students with all the necessary skills and competencies to operate with confidence and efficacy in the context of the academia. The course spanned a twelve-week period starting from midOctober to mid-January. Among the objectives of the course is to help the students to acquire macro-level skills such as organization, content and rhetorical patterns of development. It also seeks to assist the 
students to come to terms with micro-level skills such as grammar, vocabulary and mechanics. In response to local and international calls for further integration of educational technology in the teaching and learning process, the administration faculty offers its students several web-based tools to enhance their learning environment. Among such tools is Moodle, which is a learning management system including several useful features and affordances that can bring about valuable learning gains if used in pedagogically informed ways.

Of the three teachers in charge of the writing course, two were Moroccan with long-standing experience in English studies whereas the third instructor was a Full-bright visiting scholar from the USA. The role of the researcher was to coordinate with the main course teachers in order to ascertain that the follow-up activities conducted in the virtual learning environment were in consonance with the lessons that took place in the classroom. The researcher was also tasked with uploading a multitude of supplementary materials on Moodle for students to consult on a weekly basis. Besides, on the grounds that learners need constant monitoring to guarantee the sustainability of the online collaborative writing activities, it was necessary to keep track of the students' interactions and to encourage those who do not show interest in posting their assignments online and exchanging feedback with their peers.

\subsection{Participants}

Given the great number of semester-one students, it was convenient to arrange them into groups of four and ask them to build a tightly bound learning community where everyone is held accountable for the gains of the whole group. This was deemed necessary because if students were required to read and comment indiscriminately on one another's work, it would be equally hard to manage for both the students and the teacher. The students would find it hard to decide whose work to read and the teacher would not be able to monitor students' interactions and make sure that everybody is doing their fair share of the work. Therefore, the present case study selected one group for in-depth analysis including one female and three male students. The main criterion that determined the selection of this group is that it included two high-achievers and two low-achievers.

For confidentiality purposes, the participants were assigned pseudonyms; namely, Brahim, Khalid, Rashid (Males) and Fatima (Female). Brahim is 29 years old and has a BA in Arabic studies. He enrolled in the English studies department in order to enhance his English language skills for employability reasons. As a matter of course, he has a good command of standard Arabic and is reasonably literate in French. A 19-year-old, Khalid obtained his science baccalaureate the previous year and made a major shift from science studies to the humanities. Besides a fairly good proficiency level at Arabic, he has a more than average mastery of French. Opting for English studies from high school, Rashid is also 19 whose level at French is notably poor with an average command of standard Arabic. All three male students were born and raised in middle and lower-middle class families in Casablanca. Fatima constituted the exception as she came from a small village about 139 kilometers away from Casablanca and rented a flat together with other female students who had similar situations. She is 20 years old with poor French and standard Arabic literacy. All male students had a computer and internet connection at home except for Fatima, who had to go to a cyber café or a café with Wi-Fi internet connection to post her assignments and collaboratively interact with her group-mates. On the basis of the first two assignments, it turned out that Fatima and Brahim had major writing issues and thus represented the poor achievers in the case study. By contrast, performing reasonably well in the first two assignments, Khalid and Rashid assumed the role the high-achievers.

\subsection{Instructional procedure}

As indicated above in passing, three writing instructors were in charge of teaching in the onsite, faceto-face mode of instruction. The researcher assumed the role of monitor and facilitator of the online platform by uploading supplementary materials on Moodle and attending to the work performed by the students on a weekly basis. The onsite mode included a mini-lesson on a given aspect of writing such as mechanics, tenses, run-ons or fragments. The mini-lesson together with some practice was not allowed to go beyond $30 \%$ of the session's time. The remaining time was invested in developing a paragraph on a 
given topic assigned by the teacher. Brain-storming, outlining and drafting took place in the classroom under the supervision of the main course teacher. The students had to post their paragraphs online and wait for their peers' feedback. The researcher checked the feedback exchanged and provided guidance for groups who seemed to be disoriented. The students revised and edited their paragraphs in light of the feedback they obtained and posted back their finalized work.

\subsection{Data collection and analysis}

The decision to use case study methodology was driven by a number of considerations (Cohen et al, 2007). First, a case study makes it feasible to spotlight details that may be eclipsed in survey, large-scale research. Second, the close examination of one particular instance of the phenomenon being investigated can help gain generalizable insights into other similar instances of the same phenomenon. Third, the focus in case studies is not mainly on outcomes but rather on the processes that work towards the emergence of these outcomes. Four, although it is situated on the qualitative end of the continuum, case study methodology can use a variety of different methods and techniques to obtain a comprehensive and complete picture of the area under investigation.

The present study used both quantitative and qualitative tools of data collection and analysis. However, the quantitative data was kept to a minimum and had a subservient role as compared to the qualitative aspect of the study. The data were elicited by means of the students' online assignment postings and the record of the activities they performed online. The analysis of the data was carried out using t-unit-based (Hunt, 1977) indices of complexity and accuracy. The students' writing samples were subjected to content analysis to explore the elements that contributed to the progress made in complexity and accuracy.

\section{Results}

\subsection{Growth in complexity}

The first research question is concerned with the extent of the progress made in complexity and accuracy as a function of the onsite and online collaborative Moodle-hosted interactions as well as the exposure to multiple supplementary materials. Table 1 shows that all the participants seemed to be making progress in complexity except for Fatima whose scores demonstrated a good deal of variability. The main difference in the variability of the measures between Fatima and the other students lies in the fact that she did not move upwards away from the score she obtained in the first assignment. Fluctuation was also a feature of the other participants but it is a fluctuation with an upward movement, signaling slow but palpable progress. Brahim, who started out as a low-achiever, scored higher in all the measures and seemed to be moving towards closing the gap between him and the other two high-achievers. Although Khalid's scores were higher in the first assignment, Rashid outperformed Khalid in the ensuing assignments.

Table 1: Growth in complexity from the first (F) to the last (L) assignment

\begin{tabular}{|l|l|l|l|l|l|l|}
\multicolumn{1}{c|}{} & \multicolumn{2}{c|}{ MLTU } & \multicolumn{2}{c|}{ MLC } & \multicolumn{2}{c|}{ C/T } \\
\cline { 2 - 8 } \multicolumn{1}{c|}{} & F. Assig & L. Assig & F. Assig & L. Assig & F. Assig & L. Assig \\
\hline Khalid & 14.251 & 16.554 & 8.403 & 8.893 & 0.403 & 0.452 \\
\hline Rashid & 13.653 & 16.732 & 8.102 & 8.978 & 0.396 & 0.456 \\
\hline Fatima & 10.321 & 10.912 & 6.934 & 7.106 & 0.302 & 0.389 \\
\hline Brahim & 10.819 & 12.281 & 7.237 & 8.128 & 0.347 & 0.371 \\
\hline
\end{tabular}

Besides, the measure that exhibited the highest degree of syntactic maturity was MLTU. Even Fatima whose scores were not as stable as her group-mates had a slight increase in MLTU (0.591). Figure 1 displays the trajectory of progress in MLTU in every second assignment from the beginning to the end of the semester. Although Rashid and Khalid were moving in parallel lines of progress, Rashid's MLTU made 
a leap from 13.653 to 16.732 . Brahim also seemed to be progressing at approximately the same rate as Khalid (10. 819 to 12.281). As evidenced by the fluctuating line representing Fatima's progress, she reached a peak in the fourth week with a MLTU of 11.205 only to drop sharply in the eighth week to land at a MLTU of 10.333 .

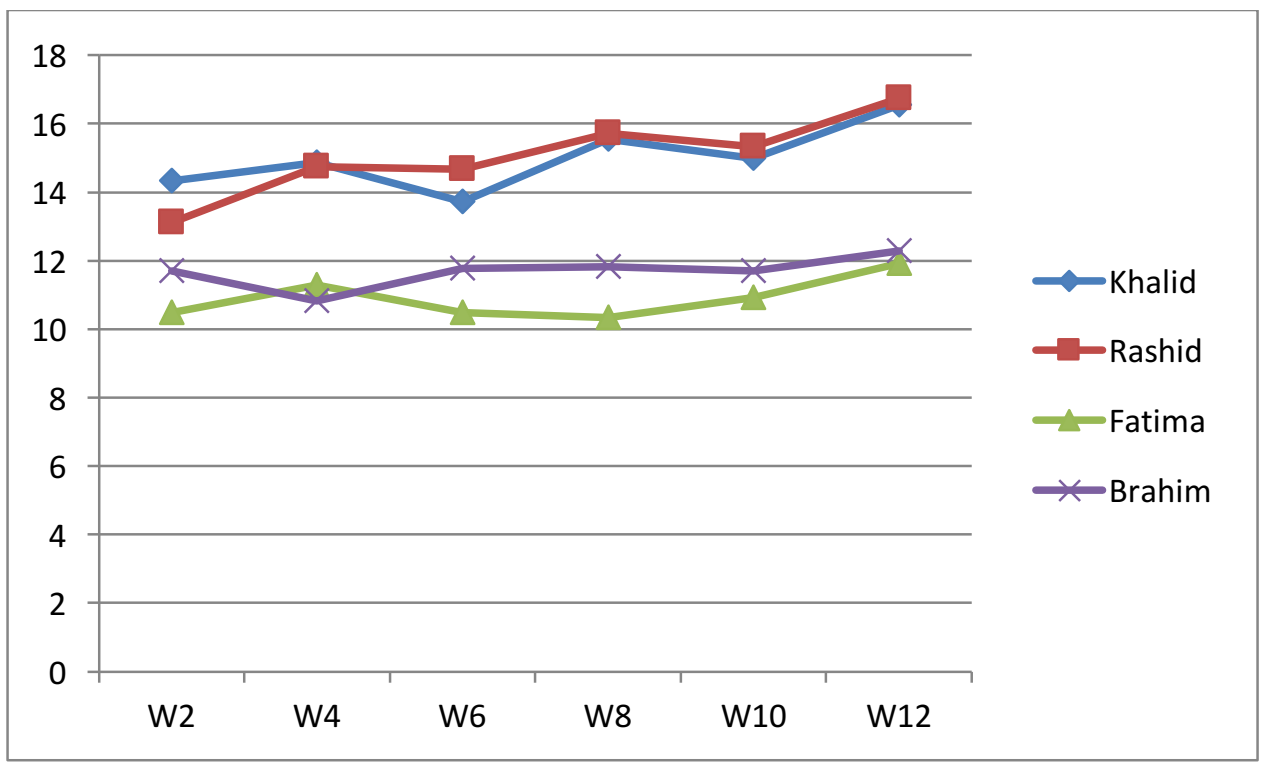

Figure 1: The trajectory of growth in MLTU from the second to the twelfth week

\subsection{The nature of the growth in complexity}

A closer examination of students' writing assignments uncovered the linguistic features that contributed to the increase in the complexity measures reported above. In terms of length, the analysis of the students writing productions revealed that although the students were in the same writing course and belonged to the same group for collaborative writing, the linguistic features that lengthened their clauses and t-units were not of the same category, which suggests that complexity was realized in idiosyncratic ways by each participant. Of the four students, three increased the length of their clauses and t-units through incorporating more non-clausal structures into main clauses. Two participants (Khalid and Rashid) seemed to have an inclination to consolidate more full clauses into nominals with adjectival, prepositional or verbal pre- or post-modifiers. To illustrate, four full clauses such as "The man was tall. The man was happily singing. The man was in the basement. The man was my uncle" were reduced by Rashid into one long eleven-word t-unit "The tall man happily singing in the basement was my uncle". The number of densely modified nominals nearly doubled for both high-achievers.

Although Fatima and Brahim were labeled as low-achievers at the start of the study, it seems that they followed dissimilar pathways in the way they grew in terms of complexity. The latter participant managed to make a long leap to come closer to Rashid and Khalid at the level of clause and t-unit length by almost equally developing the ability to lengthen structures other than nominals. Besides a noticeable increase in the number of nominal modifiers (not as sizable as that achieved by Rashid and Khalid), the average length of clauses and t-units in Braham's writings steadily increased in proportion to main verb auxiliary expansion and over-reliance on adjective clauses. An example of an expanded main verb auxiliary from one of his assignments was "The situation could have been totally reversed if ...." while his overuse of adjective clauses can be exemplified by "the doorman, who was with his club which was really big, gave a feeling of security to the residents, who were always generous with him". However, Fatima relied on simple and sometimes complex sentences with very few noun, adjective and verb modifiers. This led to the slight change observed in the length of her clauses and t-units.

Although closely followed by Brahim in terms of clause and t-unit length, Rashid and Khalid seem to outperform him with regard to another complexity-related dimension; namely, depth of modification. This means that they embedded modifiers within other modifiers inside the same clause or t-unit. In one of his assignments, Khalid wrote "my nephew delighted to have passed his exams with the confidence of an 
experienced man....". Another example from Rashid's writings was "the children assembled in the backyard trying to build a snowman with a carrot nose which they borrowed from Mrs. Latifa were hopping in jubilation". The latter example clearly shows how depth of modification served as another source of clause and t-unit lengthening. This type of modification accounted for $41 \%$ in Rashid's last assignment and $52 \%$ in Khalid's. By contrast, similar structures constituted $13 \%$ in Brahim's last assignment while none appeared in Fatima's last assignment.

\subsection{Growth in accuracy}

As can be seen from table 2, the four participants did not make as much progress as they did in complexity. Despite the slight increase observed from the first to the last assignment, an examination of all the written productions showed that the change was not linear, particularly at the intra-individual level. Interestingly, Rashid's EFT dropped sharply in assignments 3, 4, 8 to 12.5, 12.1, 12.9 respectively. Brahim's assignments also saw remarkable fluctuation so that he scored an EFT as high as 12.5 in week 8 and 11.7 in week 9. Even Fatima, gained an EFT score exceeding that obtained in her last assignment $(E F T=7.2)$. However, Khalid's written productions did not show as much variation, ranging along a continuum of 12.89 at one end and 13.8 at the other end.

Table 2: Growth in accuracy from the first to the last assignment

\begin{tabular}{|l|l|l|l|l|}
\cline { 2 - 5 } \multicolumn{1}{c|}{} & \multicolumn{2}{c|}{ EFT } & \multicolumn{2}{c|}{ EFT/T } \\
\cline { 2 - 5 } \multicolumn{1}{c|}{} & First Assign. & Last Assign. & First Assign. & Last Assign. \\
\hline Khalid & 13.1 & 13.6 & .423 & .528 \\
\hline Rashid & 13.3 & 14.5 & .492 & .577 \\
\hline Fatima & 6.5 & 6.8 & .281 & .284 \\
\hline Brahim & 7.8 & 9.61 & .301 & .441 \\
\hline
\end{tabular}

\subsection{The nature of the growth in accuracy}

The analysis of the four students' composition errors at the micro-level showed that notwithstanding an area of overlap in the error types they made, there are some error types that appeared uniquely more frequently in each participant's assignments. To chart the common errors that surfaced to an important degree in the analyzed compositions, articles ( 7 per 100 words), prepositions (5 per 100 words), verb tenses ( 7 per 100 words), and capitals ( 9 per 100 words) were identified as the most frequently occurring errors. More specifically, the students appeared to be grappling with the use of articles with regard to countable and uncountable nouns. The following examples taken from each participant's writing illustrate this type of error: "an advice; a bread; an information; a food, etc.". Besides, the prepositions that seem to present the students with the most difficulty are those that conventionally go with certain verbs, nouns and adjectives (draw on; focus on; convinced of). As for verb tenses, the distinction between closely related tenses (ex. past simple and present perfect) and the correct spelling of the past participle of irregular verbs were found to cause the students a good deal of confusion. Finally, although all the four students appeared to have mastered the basic capitalization function of starting sentences, they still missed other contexts where a capital letter is mandatory (e.g. names of mountains, lakes, cities, etc.).

As indicated above, there were other error types that emerged in one student's writings more than the others. Fatima appeared to be still operating within a low-level inter-language system as suggests the nature of the errors that she made (spelling, subject-verb agreement, fragments and run-ons). While Brahim had some of these errors to a lesser extent, he seemed to have some difficulty with adverb placement in relation to the verb it modifies (ex. she felt always sad - instead of - she always felt sad). Brahim also had a high percentage of word order errors and run-ons. By contrast, the two high-achieving students appeared to have overcome a good number of the errors predominant in their low-achieving counterparts. The most conspicuous type of error that surfaced in their writings was more lexical than grammatical; namely, word choice (she did -instead of made - a lot of progress; there is a quotation instead of proverb - that goes "..."; I am a Moroccan descent - instead of descendant). 


\subsection{Moodle log-in activities}

The third research question addresses the nature of the online activities done over a semester and the amount of time spent doing such activities. Moodle contains a feature that enables the teacher to track the online activities and the amount of time invested in each activity by each student enrolled in a given course. This information is summarized in Table 3.

Table 3: A record of the online activities and time allocations for each

\begin{tabular}{|l|c|c|c|c|c|c|}
\cline { 2 - 7 } \multicolumn{1}{c|}{} & \multicolumn{6}{c|}{ Cumulative of Time spent in minutes } \\
\cline { 2 - 7 } \multicolumn{1}{c|}{} & Videos & $\begin{array}{c}\text { Book } \\
\text { chapters }\end{array}$ & Presentations & $\begin{array}{c}\text { Feedback } \\
\text { exchange }\end{array}$ & Practice & Total \\
\hline Khalid & 67 & 456 & 105 & 903 & 382 & 1913 \\
\hline Rashid & 47 & 501 & 72 & 817 & 562 & 1999 \\
\hline Fatima & 16 & 34 & 23 & 49 & 284 & 406 \\
\hline Brahim & 77 & 492 & 98 & 1043 & 530 & 2240 \\
\hline
\end{tabular}

It can clearly be observed that the most active member of the group was Brahim, who spent 2240 minutes over a semester doing multiple online activities. He was also highly motivated with regard to feedback exchange as demonstrated the amount of time that he allocated for online discussions with his groupmates. On the contrary, Fatima did not log in as much as the rest of the group. The 16 minutes she spent on the uploaded videos showed that she watched about three out of the 20 uploaded videos. Moreover, she was the least active member during online feedback discussions (49 mn). As regards Khalid and Rashid, they showed a sustained degree of motivation towards the online activities as well as the collaborative online discussions on their written assignments.

\section{Discussion}

The present study set out to investigate the extent and nature of the growth in complexity and accuracy attained by two high-achievers and two struggling students working collaboratively in a blended writing course. The study also aimed to report on the online activities and the time spent on such activities to see whether they were reflective of the progress made in complexity and accuracy. Of the four students in the group, three attained a certain degree of growth in complexity despite the attendant variability. However, Fatima's writing complexity did not mature beyond the performance she made at the inception of the study. It was also found that each student realized complexity on the basis of different linguistic structures. Additionally, accuracy measures did not show as much growth as did complexity and the degree of variability associated with accuracy in the students' writings was comparatively greater. Differences among the participants were detected with regard to the error types that emerged in their compositions. Finally, all the students in the group had a record of online activity spanning a measurable amount of time except for Fatima.

On the basis of the results stated above, it can be understood that complexity proceeds at different rates of development both across individuals as well as at the intra-individual plane. The classification of the participants into high-achievers and low-achievers was useful as it highlighted this asymmetrical rate of development within and across these two subclasses. As for Fatima and Brahim (low-achievers), they did not grow in terms of complexity in parallel lines. Fatima seems to have stagnated at a low proficiency level as suggested the difference between her first and last assignments. By contrast, the fact that Brahim drew closer to his high-achieving group-mates insinuates that he benefitted from the blended learning environment offered by the writing course. One interpretation why Brahim's rate of growth seems to exceed that of Rashid and Khalid is that complexity as measured by length of t-units and amount of subordination has a peak that learners cannot go beyond (Hunt, 1977). At the start of the study, Rashid and Khalid were situated not relatively further away from this peak, which explains why their magnitude of growth was smaller than that of Brahim. However, Brahim started out as a low-achiever with a sizable distance away from such a peak. Besides, the variability at the intra-individual level is no less significant. Even the high-achieving students regressed in terms of complexity at certain weeks in the semester. This intra-individual variability can be ascribed to several factors such as familiarity with the topic, the structure 
of the task, time spent on the task, amount and quality of the feedback received from peers and other affective considerations (Kuiken \& Vedder, 2012).

The picture built so far on complexity is supported both theoretically and empirically. The fact that the students initially formed a heterogeneous group, which began to partly homogenize towards the end is reminiscent of the Vygotskian concept of the ZPD (Vygotsky, 1978). Vygotsky's theorizing rests on the assumption that the collaboration that occurs within a socially interacting group of students activates different ZPDs with students operating at higher proficiency ZPDs scaffolding their group-mates to reach for the next ZPD area (Pritchard \& Woollard, 2010). Empirical research offers evidence in support of this theoretical position. Dobao (2010) found that collaborative group work improved students' writing quality. While finding that collaborative work is a valuable tool to enhance students' learning, Liu and Sadler (2003) suggested that a blended learning environment may be more effective than an exclusively onsite or online mode of instruction delivery.

Another theoretical orientation supports the results obtained in the current study. According to dynamic systems theory, there is not one uniform developmental pattern to chart growth in complexity. To elucidate, Verspoor, Lowie \& Van Dijk (2008) found that although there was a general complexity increase over time in the case of an advanced learners' performance, such increase was nonlinear punctuated with moments of progress and regress. This is also consistent with Skehan's trade-off hypothesis (2009) that argues for the interplay between working memory and limited attentional resources. In other words, when a given learner's attention is dispersed over several writing aspects (e.g. complexity, accuracy and fluency), the result of such competition is for the learner to focus on one particular aspect, leaving very little room to mentally attend to other related elements. This account can be a viable explanation for the fact that the learners under study realized complexity differently. It may be the case that while producing text, the learners could only invoke a limited repertoire of linguistic resources derived from their unique educational experiences, the mini-lessons they were exposed to, their teachers, their personal reading activity together with other affective factors (Verspoor, Lowie \& Van Dijk 2008).

Contrary to previous research, the present study found that complexity increased a little faster than accuracy. Having assigned their participants to two conditions, Hartshorn et al. (2010) reported that the gains in accuracy were greater than complexity and fluency. Wigglesworth and Storch (2009) found that collaborative pair work activities had a positive impact on accuracy more than complexity. However, other studies reported that collaborative interactions among learners led to parallel developments in both complexity and accuracy. Storch (2005) found that students working in groups to jointly produce texts benefitted in several respects including growth in grammatical accuracy and complexity as well as nurturing a positive attitude towards writing. Again, invoking dynamic systems theory and the trade-off hypothesis, it can be argued that the greater attention allocated to sentence structure and an accompanying concern with sentence-combining exercises in semester one led the students to assume that they would gain more credit if they produced more complex sentence structures in their compositions. This may explain the high degree of variability in accuracy observed not only in the two low-proficient students but also in their high-proficient group-mates.

Just as complexity was realized differently by each participant, once again accuracy was found to mark each participant as distinct from the others with regard to the error types that emerged in their writings. That's why accuracy displayed a higher proportion of variability than complexity. Empirical research seems to be aligned with this finding. De Groot (2012) argued that the high variability of accuracy development is due to the many competing subsets or subsystems at the intra-individual level. While De Groot admitted the difficulty of tracing this variability back to a specific factor or set of factors, he suggested that a likely explanation would be uptake of input or exposure to the language. Similarly, the writing course teachers in the present study laid special emphasis on sentence structure, which may have diverted their students' attention away from accuracy. This situation seems to have left the students to grapple with grammatical accuracy on their own creating a group or groups of students with miscellaneous language ability.

The third research question is based on the premise that the more actively engaged in educational activities germane to curriculum subjects students are, the more likely it is that they will achieve quality academic performance. Research-based evidence exists suggesting that there is a direct correlation between students' extent of engagement in online activities and learning outcomes (Wong, 2013). Engagement in the present study was operationalized in terms of amount of time invested in online 
activities by each participant. In this regard, it appears that the amount of time Fatima invested in online activities including the exchange of feedback with her group-mates has a relationship with her low-level performance over the semester. An examination of Fatima's profile readily provides clues as to why she did not engage as actively as the other students in the online activities. It was reported that she came from a small village and had to rent an apartment with other girls. It was also mentioned that she did not have internet connection and a computer at home, which forced her to pay repeated and costly visits to a cyber café to joint in the online discussions and activities as well as to post her assignments. In stark contrast to Fatima's degree of engagement in online activities, Brahim made noticeable gains in complexity and accuracy. A quick look at the number of minutes he allocated for diverse online activities would suggest that they had an impact on his performance over the semester.

\section{Conclusion and Implications}

In a nutshell, the present study investigated the extent and nature of the progress made by two highachieving and two struggling students working collaboratively in a blended learning environment to enhance their writing ability. Measurement of writing ability was carried out on the basis of empirically motivated indices of complexity and accuracy. The study also explored the degree of students' engagement in online activities to ascertain whether or not this had a relationship with the growth attained in complexity and accuracy. It was found that although there was some progress in complexity and accuracy, a high rate of variability was detected both inter- and intra-individually. This variability was notably higher in accuracy with each student grappling with a unique set of error types. Finally, a relationship seems to hold between the students' extent of engagement with the online activities and the growth attained in complexity and accuracy. This was reflected, on the one hand, by Fatima's weak performance over the semester and the amount of time she spent in the online activities. On the other hand, the progress made by the other participants, especially Brahim, was proportionate with the extent of the time investment that went into the multiple Moodle-hosted activities.

In light of the results reported above, a number of implications are in order. In consonance with constructivist theory, onsite and online collaborative learning environments should bring together students of different proficiency levels. As was found in the present study, high-proficient students can help their struggling group-mates notice their language problems during sessions of feedback exchange and hopefully try to avoid them in future assignments. The question that arises in this regard is the extent to which high-achieving students can benefit from such a situation. It can be argued that the mere process of reading other students' written productions in order to provide feedback offers the high-achieving students an opportunity to reinforce their learning. However, the fact that Fatima did not benefit from online group work does not so much mean collaboration cannot work for a certain category of students as it arguably calls to attention the issue of connectivity and inclusivity. Successful implementation of an online instruction based on peer collaboration requires that the educational authorities invest in infrastructure and equipment to help students of poor social backgrounds find facilities within the university premises where they can join their socially more fortunate group-mates in online activities. Additionally, given the asymmetrical development of complexity and accuracy both inter- and intra-individually, more efforts need to be deployed in designing syllabuses that incorporate all the major components of effective writing instruction. This will help distribute students' attention evenly over all such components to ensure that complexity and accuracy are given equal weighting.

\section{References}

Cohen, L., Manion, L., \& Morrison, K. (2007). Research methods in education (4 $4^{\text {th }}$ Ed.). London: Routledge.

De Groot, F. O. (2012). Intra-Individual learner variation in English L2 writing: A case study of complexity, and accuracy development in intensive English language programs. FLLT Journal, 1(1).

Dobao, F. A. (2012). Collaborative writing tasks in the L2 classroom: Comparing group, pair, and individual work. Journal of Second Language Writing, 21(1), 40-58. 
Hicham Zyad

Elola, I., \& Oskoz, A. (2010). Collaborative writing: Fostering foreign language and writing conventions development. Language Learning \& Technology, 14, 51-71.

Ennaji, M. (2005). Multilinguilism, cultural identity and education in Morocco. New York: Springer.

Haoucha, M. (2005). The effects of a feedback-based instruction programme on developing EFL writing and revision skills of first-year university students. University of Warwick: Warwick.

Hartshorn, K. J., Evans, N. W., Merrill, P. F., Sudweeks, R. R., Strong-Krause, D., \& Anderson, N. J. (2010). Effects of dynamic corrective feedback on ESL writing accuracy. TESOL Quarterly, 44, 84-109.

Hunt, k. (1977). Early blooming and late blooming syntactic structures. In C. R. Cooper, \& L. Odell (Eds.), Evaluative writing: Desccribing, measuring and judging (pp. 91-104). Urbana: National Council of teachers of English.

Jones, R. H., Garralda, H., Li, C. S., \& Lock, G. (2006). Interactional dynamics in online and face-to-face peer-tutoring sessions for second language writers. Journal of Second Languge Writing, 15, 1-23.

Kessler, G., Bikowski, D., \& Boggs, J. (2012). Collaborative writing among second language learners in acedemic web-based projects. Language Learning \& Technology, 16(1), 91-109.

Kuiken, F., \& Vedder, I. (2012). Syntactic complexity, lexical variation and accuracy as a function of task complexity and proficiency level in L2 writing and speaking. In A. Housen, F. Kuiken, \& I. Vedder (Eds.), Dimensions of $L 2$ performance and proficiency: Complexity, accuracy and flunecy in SLA (pp. 143-169). Philadelphia: John Benjamins North America.

Liu, J., \& Sadler, R. W. (2003). The effect and affect of peer review in electronic verses traditional modes on L2 writing:. Journal of English for Academic Purposes, 2, 193-227.

Neumann, H., \& McDonough, K. (2014). Exploring student interaction during collaborative prewriting discussions and text quality in an EAP context. Journal of English for Academic Purposes(15), 14-26.

Palincsar, A. S. (1998). Social constructivist perspectives on teaching and learning. Annual Reviews Inc., $49,345-375$

Pritchard, R., \& Honeycutt, R. (2006). The process approach to writing instruction. In C. McArthur, S. Graham, \& J. Fitzgerald (Eds.), Handbook of writing research (pp. 275-292). New York: Guilford Press.

Skehan, P. (2009). Modelling second language performance: Integrating complexity, accuracy, fluency, and lexis. Applied Linguistics, 30, 510-532.

Storch, N. (2005). Collaborative writing: Product, process, and students' reflections. Journal of Second Language Writing, 14, 153-173.

Tuzi, F. (2004). The impact of e-feedback on the revisions of L2 writers in an academic writing course. Computers \& Composition, 21(2), 217-235.

Verspoor, M., Lowie, W., \& Van Dijk, M. (2008). Variability in second language development from a dynamic systems perspective. The Modern Language Journal, 92(2), 214-231.

Vygotsky, L. S. (1978). Mind in society. Cambridge, MA: Harvard University Press.

Wong, L. (2013). Student engagement with online resources and its impact on learning outcomes. Journal of Information Technology Education: Innovation in Practice, 12, 129-146.

Zhang, H., Song, W., \& Huang, R. (2014). The effects pf blog-mediated peer feedback on learners' motivation, collaboration and course satisfaction in a second language writing course. Australian Journal of Educational Technology, 30(6), 670-685.

Fecha de recepción / Received: 09/03/2016

Fecha de aceptación / Accepted: 31/03/2016 